\title{
Improved science learning outcomes of animal life cycle materials using audio- visual media in grade $\mathrm{V}$
}

\section{Fitriani}

SD Negeri 2 Tambakmulyo

fitrya63@gmail.com

\section{Article History}

accepted 14/11/2020

approved $21 / 11 / 2020$

published 26/11/2020

\begin{abstract}
The purpose of this study was to improve the learning outcomes of class $V$ students in science subject matter animal life cycle material. This research is a Classroom Action Research which is conducted in two cycles with the stages of each cycle being planning, implementing action, observing and reflecting. The subjects of this study were students of class VA SD Negeri 2 Tambakmulyo for the 2020-2021 school year. There were 24 students. Data collection techniques using observation and tests. The conclusion of this study is that the use of audiovisual media can improve science learning outcomes in grade V SD Negeri 2 Tambakmulyo for the 2020/2021 academic year. This is evidenced by the percentage of learning completeness in the first cycle of $62.5 \%$ and in the second cycle it increased to $91.27 \%$. The class average in the first cycle was 74.58 and the second cycle increased to 77.91.
\end{abstract}

Keywords: learning outcomes, audio-visual media, science

\section{Abstrak}

Tujuan penelitian ini adalah untuk meningkatkan hasil belajar peserta didik kelas $\mathrm{V}$ pada muatan pelajaran IPA materi daur hidup hewan. Penelitian ini merupakan Penelitian Tindakan Kelas yang dilaksanakan dalam dua siklus dengan tahapan tiap siklusnya adalah perencanaan, pelaksanaan tindakan, observasi dan refleksi. Subjek penelitian ini adalah peserta didik kelas VA SD Negeri 2 Tambakmulyo tahun pelajaran 2020-2021. Peserta didik berjumlah 24 anak. Teknik pengumpulan data menggunakan observasi dan tes. Kesimpulan dari penelitian ini adalah bahwa penggunaan media audio visual dapat meningkatkan hasil belajar IPA pada peserta didik kelas V SD Negeri 2 Tambakmulyo Tahun Pelajaran 2020/2021. Hal ini dibuktikan dengan persentase kekutantasan belajar pada siklus I sebesar $62,5 \%$ dan pada siklus II meningkat menjadi $91,27 \%$. Rata-rata kelas pada siklus I sebesar 74,58 dan pada siklus II meningkat menjadi 77,91 .

Kata kunci: hasil belajar, media audio visual, IPA

Social, Humanities, and Education Studies (SHEs): Conference Series https://jurnal.uns.ac.id/shes 


\section{PENDAHULUAN}

SD Negeri 2 Tambakmulyo adalah salah satu sekolah yang terdampak pandemi covid 19. Keadaan ini menyebabkan adanya perubahan sistem pembelajaran. Salah satu kebijakan yang diambil sekolah adalah pembelajaran dalam jaringan (daring). Perubahan pada sistem pembelajaran merupakan tantangan bagi guru dan juga peserta didik. Sarana dan prasarana menjadi hal pokok yang harus dipenuhi agar pembelajaran dapat dilaksanakan dengan baik.

Dalam pembelajaran IPA khususnya materi daur hidup hewan, muncul beberapa permasalahan di kelas diantaranya: (1) rendahnya minat belajar peserta didik, (2) rendahnya keaktifan peserta didik dalam pembelajaran, (3) rendahnya hasil belajar peserta didik. Hal tersebut diperkuat dengan persentasi ketuntasan belajar di kelas VA sebesar $37,5 \%$, sedangkan rata-rata kelas adalah 67,5 .

Permasalahan yang muncul dalam pembelajaran di duga karena: (1) pembelajaran yang dilaksanakan masih konvensional, (2) tidak adanya variasi media yang digunakan dalam proses pembelajaran.

Untuk mengatasi permasalah tersebut, penulis mencoba melakukan perbaikan pembelajaran menggunakan media audio visual. Media pembelajaran adalah alat, metode dan teknik yang digunakan dalam rangka lebih mengefektifkan komunikasi dan interaksi antara guru dan peserta didik dalam proses pendidikan dan pengajaran di sekolah (Hamalik, 1986). Media pembelajaran berbasis audio-visual adalah media penyaluran pesan dengan memanfaatkan indera pendengaran dan penglihatan (Rusman, 2012).

Berdasarkan uraian di atas, penulis mencoba melakukan penelitian dengan judul Peningkatan Hasil Belajar IPA Materi Daur Hidup Hewan menggunakan Media Audio Visual pada Siswa Kelas V. Tujuan penelitian ini adalah untuk meningkatkan hasil belajar peserta didik pada materi daur hidup hewan.

\section{METODE}

Penelitian ini merupakan penelitian Tindakan kelas (PTK) yang dilaksanakan dalam dua siklus. Setiap siklus terdiri dari perencanaan, pelaksanaan tindakan, observasi dan refleksi. Penelitian dilaksanakan di SD Negeri 2 Tambakmulyo Kecamatan Puring Kabupaten Kebumen. Subjek penelitian ini adalah peserta didik kelas VA SD Negeri 2 Tambakmulyo Tahun Pelajaran 2020-2021 yang berjumlah 24 anak. Penelitian dilaksanakan pada bulan november 2020.

Data yang dianalisis adalah data kuantitatif yaitu data hasil belajar peserta didik. Teknik pengumpulan data menggunakan tes. Evaluasi dilaksanakan setelah proses pembelajaran dengan menggunakan media audio visual selesai dilaksanakan. Aspek kognitif yang diukur terdiri dari level C4 sampai dengan C6.

\section{HASIL DAN PEMBAHASAN}

Pada penelitian yang telah dilakukan dalam dua siklus ini, ketuntasan belajar dan rata-rata kelas VA meningkat dari siklus I ke siklus II. Hal ini dapat dilihat pada tabel berikut: 
SHEs: Conference Series 3 (3) (2020) 887- 891

Tabel 1. Hasil belajar peserta didik siklus I dan siklus II

\begin{tabular}{|c|c|c|c|c|}
\hline Nilai & $\begin{array}{c}\text { Siklus I } \\
\text { Frekuensi }\end{array}$ & Persentasi & $\begin{array}{c}\text { Siklus II } \\
\text { Frekuensi }\end{array}$ & Persentasi \\
\hline 100 & 4 & $16,67 \%$ & 4 & $16,67 \%$ \\
\hline 90 & - & $0 \%$ & 2 & $8,33 \%$ \\
\hline 80 & 5 & $20,83 \%$ & 6 & $25 \%$ \\
\hline 70 & 6 & $25 \%$ & 10 & $41,67 \%$ \\
\hline 60 & 4 & $16,67 \%$ & 1 & $4,17 \%$ \\
\hline 50 & - & $0 \%$ & 1 & $4,17 \%$ \\
\hline 40 & 5 & $20,83 \%$ & - & $0 \%$ \\
\hline Jumlah & \multirow{2}{*}{\multicolumn{2}{|c|}{$\begin{array}{c}24 \\
74,58\end{array}$}} & \multicolumn{2}{|c|}{24} \\
\hline Rata-rata & & & & \\
\hline Tuntas & \multicolumn{2}{|c|}{$62,5 \%$} & \multicolumn{2}{|c|}{$91,7 \%$} \\
\hline
\end{tabular}

Berdasarkan tabel di atas, dapat kita ketahui bahwa ketuntasan belajar dan rata-rata nilai kelas VA meningkat pada siklus dan siklus II. Untuk lebih jelasnya hasil siklus I dan siklus II dapat dilihat pada digram berikut:

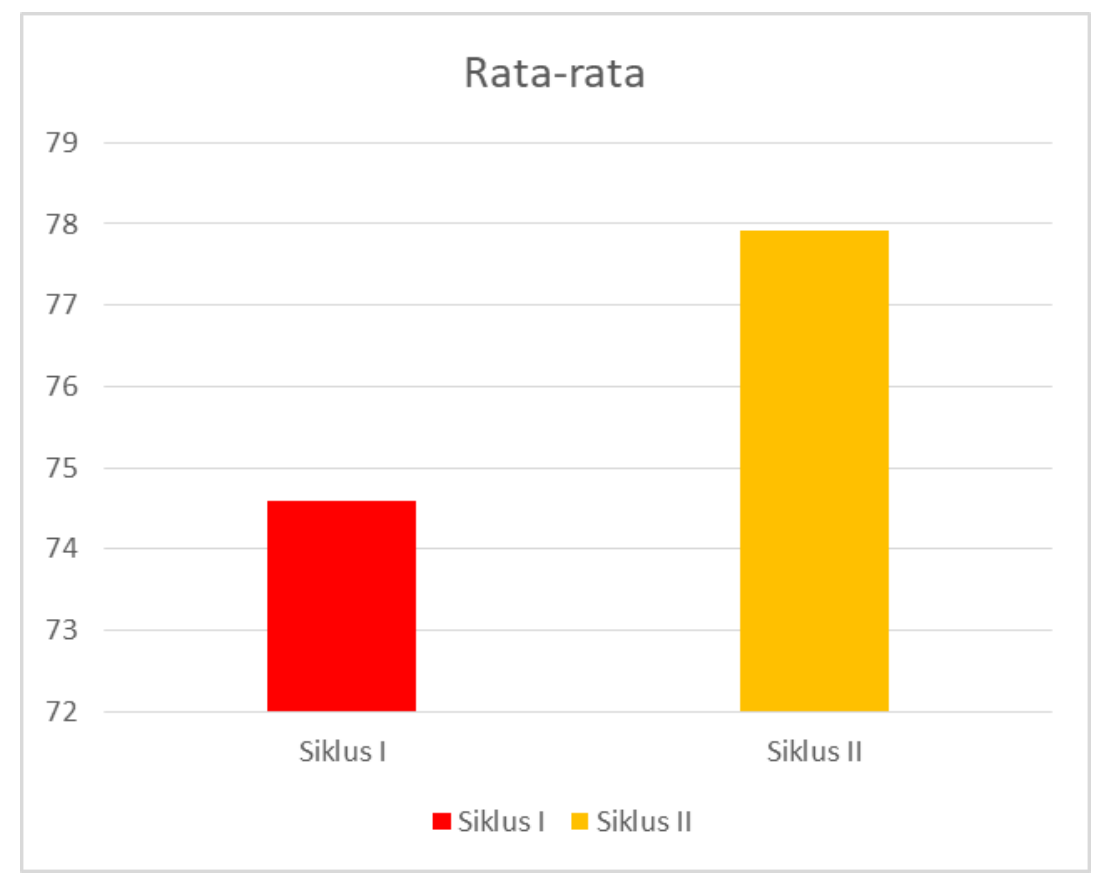

Gambar 1. Rata-rata nilai kelas V

Berdasarkan gambar 1, dapat dilihat bahwa rata-rata kelas pada siklus I adalah 74,58 dan pada siklus II meningkat menjadi 77,91. 


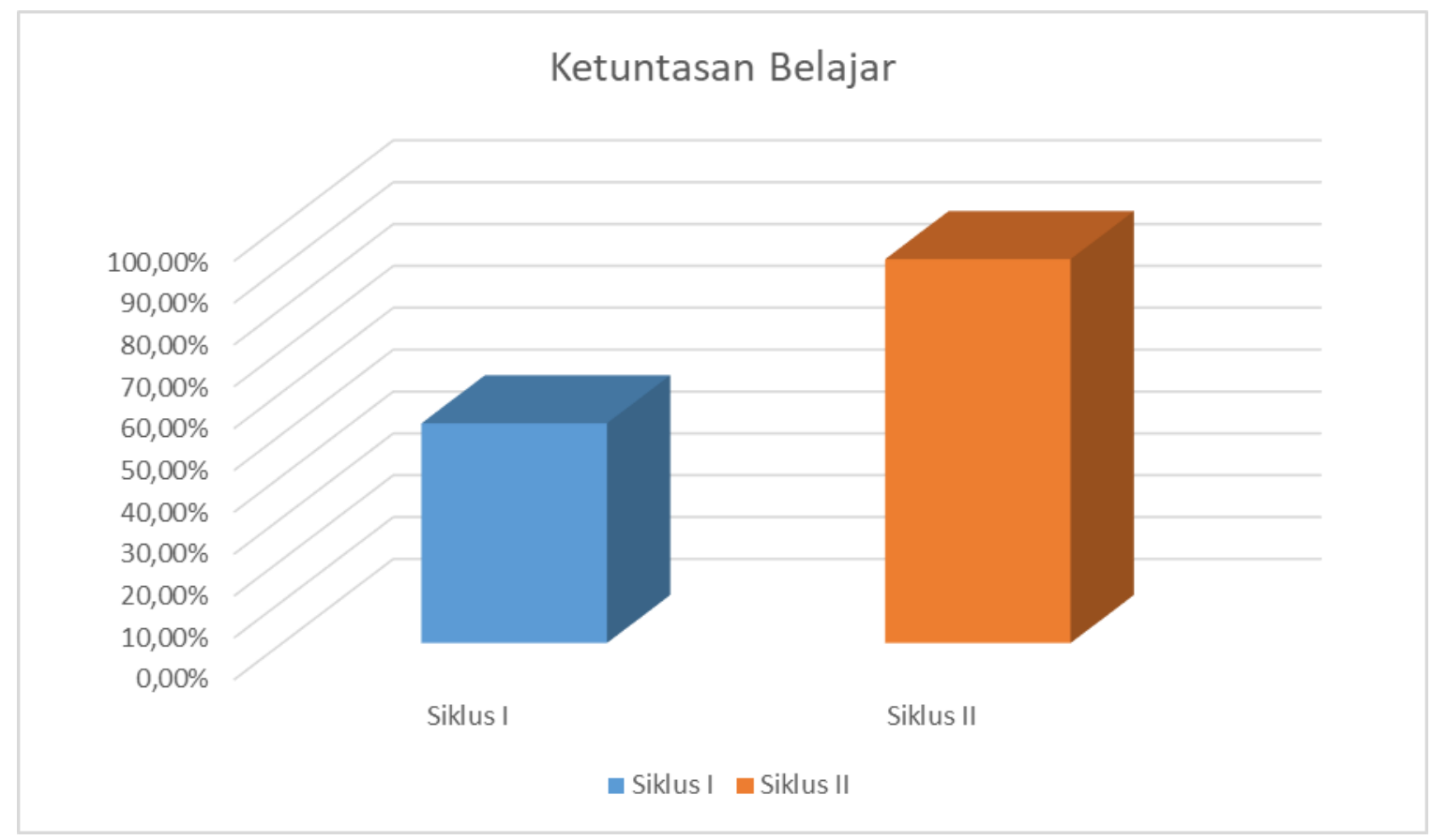

Gambar 2 Ketuntasan belajar siswa

Berdasarkan diagram di atas, dapat kita lihat bahwa ketuntasan belajar pada siklus I adalah $52,5 \%$ dan meningkat menjadi $91,7 \%$ pada siklus II.

Penggunaan media audio visual pada pembelajaran dapat meningkatkan hasil belajar peserta didik kelas VA SD Negeri 2 Tambakmulyo secara signifikan. Pada hasil penilaian sebelum dilaksanakan tindakan penelitian, sebanyak 14 dari 24 peserta didik belum mencapai KKM dengan persentase ketuntasan belajar $41 \%$ dan rata-rata kelas adalah 62,5. Setelah dilakukan tindakan, persentasi ketuntasan belajar meningkat menjadi $62,5 \%$ dengan rata-rata kelas 74,58 . Pada siklus II ketuntasan meningkat menjadi $91,7 \%$ dengan rata-rata kelas 77,91 . Ketuntasan belajar pada siklus II mencapi $91,7 \%$ dengan KKM 70 sudah memenuhi indikator kinerja. Sehingga penelitian dihentikan pada siklus II.

Berdasarkan hasil analisis hasil belajar peserta didik setelah pelaksanaan tindakan, dapat diambil kesimpulan bahwa penggunaan media audio visual dapat meningkatkan hasil belajar IPA materi daur hidup hewan. Hal ini sesuai dengan penelitian yang dilakukan oleh Maria Ria membuktikan bahwa penggunaan media audio visual dapat meningkatkan hasil belajar IPA kelas V. Hasil penelitian ini juga memperkuat pendapat Musfiqon (2012 ) bahwa pembelajaran yang menggunakan multimedia telah terbukti lebih efektif dan efisien serta bisa meningkatkan hasil belajar siswa.

\section{SIMPULAN}

Berdasarkan hasil penelitian dan uraian pembahasan maka dapat diambil simpulan sebagai berikut:

Penggunaan media audio visual pada pembelajaran IPA materi daur hidup hewan dapat meningkatkan minat belajar peserta didik kelas VA SD Negeri 2 Tambakmulyo tahun pelajaran 2020/2021. Hal ini berpengaruh pada peningkatan hasil belajar peserta didik setelah dilaksanakannya tindakan. Ketuntasan belajar peserta didik yang semula hanya $62,5 \%$ pada siklus I meningkat menjadi $91,7 \%$ pada siklus II. Sedangkan rata-rata kelas pada siklus I 74,58 meningkat menjadi 77,91 pada siklus II.

Pada penelitian yang dilakukan, penulis melibatkan peserta didik secara aktif dalam kegiatan pembelajaran yang menggunakan teknologi media audio visual 
sehingga peserta didik lebih mudah memahami materi yang berdampak pada peningkatam hasil belajar. Sekolah hendaknya memberi dukungan secara penuh kepada guru untuk mengembangkan berbagai variasi pembelajaran.

\section{DAFTAR PUSTAKA}

Anonim. 2009. Himpunan Peraturan Perundang-Undangan UNDANG-UNDANG SISDIKNAS. Bandung: Fokusmedia

Arikunto, Suharsimi, dkk. 2009a. Penelitian Tindakan Kelas. Jakarta : PT Bumi Aksara Hamalik, Oemar 1986 Media Pendidikan. Bandung: Alumni.

Hamalik, Oemar 2014 Kurikulum dan Pembelajaran. Jakarta: Bumi Aksara.

Musfiqon. (2012). Pengembangan Media \& Sumber Pembelajaran. Jakarta. Prestasi Pustaka Raya

Sukiman. Pengembangan Media Pembelajaran. Yogyakarta: Pedagogia 